material. M. Ralska-Jasiewiczowa counted pollen sums from over $500 \mathrm{P}$ (in Late-Glacial spectra) to $2000 \mathrm{P}$ and rarely more, on average around $1000 \mathrm{P}$ per sample. $\mathrm{B}$. van Geel counted mostly 300-500 P and all the non-pollen microfossils found on the same slide surface. The pollen counts were then summed up in each sample.

This procedure had some advantages, e.g. possibilities to compare the qualitative and quantitative composition of pollen spectra generated from the same material by two different pollen analysts, and then to check possible differences once again; to compare the composition of pollen spectra when based on different pollen sums; and to get a pollen diagram based on a P-sum higher than commonly produced.

Some difficulties were caused by the sometimes different approaches of the two analysts to pollen identification, taxonomy, and nomenclature. When possible, such identifications were then checked and harmonized. In rare cases when this was impossible, different pollen curves representing counts of the two analysts within the same taxonomic group appear in the diagram (e.g. Secale cereale and other cereal types, and Secale/Cerealia pollen curves in the GF profile). An attempt was made to adopt the recommendations of the European Pollen Database (Gaillard et al. msc.) concerning nomenclature of pollen taxa, but this was not always possible.

The calculation of the pollen-analytic results and construction of pollen-percentage and pollen-influx diagrams follow generally the recommendations proposed by Berglund and Ralska-Jasiewiczowa (1986). All diagrams except for the Late-Glacial G28/92 profile and the bottom part of T1/90 profile are based on calendar time scales. The data obtained by M. Ralska-Jasiewiczowa and B. van Geel were handled by A. Walanus and T. Goslar, and most pollen diagrams were drawn using the POLPAL-for Windows program (Walanus 1995, Walanus \& Nalepka 1996). Some diagrams were produced by D. Demske with the plotting program TILIA-GRAPH version 1.25 (Grimm 1992), and the zonation of the diagrams was supported by the CONISS cluster analysis belonging to the TILIA program.

\subsubsection{Plant-Macrofossil analysis}

\section{Dieter Demske}

Samples of 25 or $50 \mathrm{~cm}^{3}$ were dispersed in water and washed on a sieve with $0.2 \mathrm{~mm}$ mesh. In case of calcareous material samples were pre-treated with $10 \% \mathrm{HCl}$. After segregation in water, the material was preserved in a mixture of water, alcohol and glycerine 1:1:1 with addition of thymol (Wasylikowa 1986). After the taxa were determined the data were recalculated for a standard volume of $25 \mathrm{~cm}^{3}$. The diagram was plotted with the TILIAGRAPH program.

\subsection{CLADOCERA ANALYSIS}

\section{Krystyna Szeroczyńska}

The sediments of cores G1/87 and G1/90 were sampled as described in Chapter 4.1.3. The Late-Glacial part was sampled every 6 varves. In the Holocene part sampled with the time resolution of 50 years each sample includes 10 varves. The core T1/90 was sampled in cubic centimetres. Samples used for analysis of cladoceran remains were treated with a few drops of $4 \%$ formalin and stored in a refrigerator to prevent the growth of bacteria and fungi. The cladoceran remains were prepared according to Frey's method (1986a, b). Each sample was boiled for half an hour in a $10 \%$ solution of $\mathrm{KOH}$ to remove humic matter after elimination of carbonates by $\mathrm{HCl}$. The residue was washed with distilled water over a $50 \mu \mathrm{m}$ sieve. The final residue was filled up to $15 \mathrm{~cm}^{3}$ with distilled water, containing a few drops of formalin and saffranin. For preparation of microscope slides $0.05 \mathrm{ml}$ of this solution was used. All skeletal parts were counted: headshields, shells, postabdomen, postabdominal claws, antennules, antennal segments, mandibles, and ephippia. 3-7 slides were counted from each sample, depending on the abundance of remains. When a sample was very rich in remains and frequency exceeded 500 specimens, only two slides were examined, and the average result calculated. The results of qualitative and quantitative analyses are presented in a percentage diagram and in a concentration diagram, in which for each sample an absolute number of specimens was calculated for $1 \mathrm{~cm}^{3}$ of sediment. The next stages of research were based on the number of specimens recorded. Sources by Flössner (1972) and Smirnov $(1971,1978)$ and the systematical analyses by Frey $(1958,1959,1962,1980)$ and Goulden $(1964 a, b)$ were used to determine the species found.

The method as described above was applied to samples from all cores to enable comparison.

\subsection{DIATOM ANALYSIS}

\section{Barbara Marciniak}

The samples for diatom analysis were macerated according to methods applied to sediments rich in calcium carbonate and organic substances (Siemińska 1964). 1000 diatoms were counted in each sample, and the diagram showing percent content (i.e. relative frequency) of the dominant and subdominant diatoms as well as less frequent ones was plotted. The groups of euplanktonic, littoral-planktonic, and periphytic diatoms were presented in a separate diagram. The diagrams were plotted with a computer program (POLPAL) elaborated earlier for the purposes of palynological studies (Ralska-Jasiewiczowa \& Walanus 1989, 1991, Walanus 1989) and then adapted for diatom analysis by A. Walanus. 